multiplicity of small purchasing entities will create a nightmare of bureaucracy and subsequent waste without any clear benefit to patients in most cases.

The saddest and most threatening aspect of these guidelines, however, is the attitude towards cooperation between providers, which in future is to be looked on as collusion. The glory of the NHS has been the freedom with which clinicians, nurses, and workers in ancillary branches have been able to cooperate, to share, and thus to promote advances in treatment to the great benefit of patients generally and to ensure (through an equitable, national wage structure) a high and uniform standard of care throughout Britain. The market ethos with its suspicion of collusion and "industrial" espionage could destroy all that. I hope that readers will resolve to resist any attempt to limit their freedom to continue to cooperate with colleagues and to press for rational allocation of services in their districts and regions. At the same time a critical eye should remain firmly fixed on management and its costs, which have so dramatically increased since the onset of the reforms.

C A PORTER

Paediatric Department,

William Harvey Hospital

Ashford,

Kent TN24 0LZ

1 Le Grand J. Internal market rules OK. BMF 1994;309:1596-7. (17 December.)

\section{Effect size}

EDITOR,-In their article on the development of a symptom based outcome measure for asthma Nick Steen and colleagues erroneously define effect size as the difference between baseline and follow up scores divided by the standard error of baseline scores. ${ }^{1}$ This is incorrect: the effect size is the difference between baseline and follow up scores divided by the standard deviation of baseline scores. ${ }^{2}$ This mistake has been made by others. ${ }^{3}$

The purpose of calculating effect size is to determine whether a change in health status is clinically relevant and to permit comparison with other instruments, interventions, or studies. If the standard error of baseline scores is used as the denominator the effect size will increase roughly in proportion to the square root of the number of subjects in the study, negating these advantages. Guyatt et al recommended using twice the average within subject standard error derived from two or more baseline observations as the denominator to derive an index of an instrument's responsiveness. This index would increase roughly in proportion to the square root of the number of replicate baseline observations.

COLIN BORLAND Consultant physicia

Hinchingbrooke Hospital,

Huntingdon,

Cambridgeshire PE18 8NT

1 Steen N, Hutchinson A, McColl E, Eccles MP, Hewison J, Meadows KA, et al. Development of a symptom based outcome measure of asthma. BMF 1994;309:1065-8. (22 October.)

2 Kazis LE, Anderson JJ, Meenan RF. Effect sizes for interpreting changes in health status. Med Care 1989;27:S178-89.

3 Fletcher A, Gore S, Jones D, Fitzpatrick R, Spiegelhalter D, Cox D. Quality of life measures in health care. II. Design, analysis, and interpretation. BMF 1992;305:1145-8.

4 Guyatt G, Walter S, Norman G. Measuring change over time: assessing the usefulness of evaluative instruments. I Chronic Dis 1987;40:171-8.

\section{Young people and drug misuse}

EDrroR,-J Denham Wright and Laurence Pearl highlight the apparently increasing trend for young people to engage in illicit drug misuse. ${ }^{1}$ There are, however, problems with the methods, analyses, and conclusions of their study. A large generation and ideological gap exists between people who conduct this type of scientific inquiry and those who are the subjects of the research. Unfortunately, this is reflected in the design of the questionnaire, which opens with the question, "What drugs taken by addicts do you know?" While the word "addict" might reflect the social and moral mores of the late $1960 \mathrm{~s}$, its use nowadays to refer to young people who experiment with drugs is inaccurate and could be perceived as being derogatory. This can serve only to increase the gulf between the researcher and the researched, and as an opening gambit it casts doubt on the validity of the remainder of the research instrument.

The authors refer to television as being the main source of information about drugs and proceed to give recommendations to television producers on the basis of this. In fact, the main source of young people's information about drugs cannot be ascertained from this questionnaire since the question was "Where did you first hear about drugs?" The initial source of information and main source of information are not synonymous and should not be treated as such. The categorisation of responses to question 7- "Why do you think young people take drugs?"-is also dubious: some of the response categories seem semantically jumbled.

The authors quote Cohen as stating that primary prevention strategies have not reduced drug use among young people. ${ }^{2}$ It would, I believe, be more accurate to state that the failures of traditional approaches to prevention or reduction were based on faulty assumptions, a lack of methodological rigour, and ignorance of young people's lives. There is, however, evidence that primary prevention programmes can work. ${ }^{3}$

Addressing the problem of young people and drugs requires competent interdisciplinary research that uses a combination of inductive and deductive research methods as a starting point Quality control must be built in from the start. Without this, primary prevention approaches will have less than optimal chances of succeeding.

\section{MERVYN GIFFORD}

Department of Public Health Medicine,

MERVYN GIFFORD

Eastern Health and Social Services Board,

Belfast BT2 8BS

1 Denham Wright J, Pearl L. Knowledge and experience of young people regarding drug misuse, 1969-94. BMf 1995;310:20-4 (7 January.)

Cohen $\mathrm{J}$. Achieving a reduction in drug related harm throug education. In: Heather N, Wodak A, Nadelman E, O'Hare P eds. Psychoactive drugs and harm reduction: from faith to science London: Whurr, 1992.

3 Tobler N. Drug prevention programmes can work: research findings. F Addict Dis 1992;11(3):1-28.

4 Altman D. The scandal of poor medical research. $B M F 1994 ; 308$ : 283-4.

\section{Press release of the week}

EDrToR,-I hope that Patricia Macnair's views regarding the press release announcing a "major genetic breakthrough for Noonan syndrome" are not representative of those held at the $B M \mathcal{F}$. The discovery of a gene, whether for a rare condition like Noonan syndrome or for something much more common like breast cancer, is a majo breakthrough for those at risk or affected. It shows that progress is being made and provides hope for the future. Publicity helps to communicate news of the discovery to those who might wish to know about it for personal or professional reasons and also to those who may be able to help raise funds to enable researchers to make further progress towards developing diagnostic tests and perhaps even a cure. The discovery of the structure of a gene is also a permanent addition to knowledge that will have timeless relevance, unlike some medical news afforded much greater prominence in the lay or professional press.
Macnair might consider why it is necessary to present the information in the way that it was presented. If the release had been headed "Minor advance for those with obscure disease-not many interested" I doubt that many people would have been moved to read it. The media make the rules about inclusion. The $B M f$ should not take the high moral ground if those with something to say play by those rules.

ALASTAIR KENT

Director

Genetic Interest Group

London EC1M 3JB

1 Macnair P. "Major genetic breakthrough for Noonan syndrome." $B M f$ 1995;210:67. (7 January.)

\section{Eradicating fleas}

EDITOR,-As a pet owner and therefore a hierarchical owner of cat and dog fleas as well as a past user of aldrin and dieldrin (so only a pallid "green"), I will try to help Jacqueline Currey's carpets, if not her bites. ${ }^{1}$ A relative who worked worldwide in agricultural pest control passed several tips on to me.

The house-Fleas breed in warm weather, and the pupas hatch simultaneously when stimulated by vibration (which equals good news to fleas, indicating that there is a meal about). So, on return from holiday, a room that has been the favoured snoozing place for pets can suddenly be "a-hop."

Cure-Purchase dichlorvos (Vapona) vapour strips appropriate to the largest room in the house: one strip controls about $56 \mathrm{~m}^{2}$. Circulate the fresh strips, night by night, from room to room. The vapour is quite irritant, so close the doors well. Cats particularly are upset by it. Remember to treat the places, especially the airing cupboard, where pets spend time. This treatment acts on all stages of development of fleas: egg, larva, pupa, and imago. It penetrates into nooks and crannies and goes deep into carpet pile. Vacuuming leaves a suspect $2 \mathrm{~cm}$ around the skirting board and cleans only the surface pile of a carpet.

The pets-An old fashioned derris bath controls the animals' infestation. Make sure to get it well on the head and round the neck. It is amazing to see the number of dead fleas floating on the water afterwards. Let the derris dry on the animal, without rinsing. It leaves the bath in a disgusting state afterwards, alas.

A similar technique will control furniture beetle (woodworm) in lofts during the beetles' breeding flights in May.

BRUCE WILLIAMSON

Melton Mowbray,

Leicestershire LE13 ONT

1 Currey J. Come back DDT-all is forgiven. BMf 1994;309: 1692. (24-31 December.)

\section{Correction}

\section{Severe chickenpox during treatment wrth} corticosteroids

Justin Bendig and colleagues have pointed out that the subtitle given by the editorial staff to their letter on this subject "Commercial assays have high false positive rate"; 4 February, pp 327-8) is misleading. A more appropriate subtitle would have been "Latex assay shows false negatives."

\section{Smoking and death}

An editorial error occurred in this letter by Rodolfo Saracci (4 March, p 600). Parts (a) and (b) of the published figure are transposed and do not correspond to the legend or citations in the text. Therefore, the last sentences of the second and third paragraphs refer to part $(b)$ of the published figure and the penultimate sentence refers to part $(a)$. 